\title{
Building a maintenance policy through a multi-criterion decision-making model
}

\author{
Elahe Faghihinia ${ }^{{ }^{*}}$ and Naser Mollaverdi ${ }^{2}$
}

\begin{abstract}
A major competitive advantage of production and service systems is establishing a proper maintenance policy. Therefore, maintenance managers should make maintenance decisions that best fit their systems. Multi-criterion decision-making methods can take into account a number of aspects associated with the competitiveness factors of a system. This paper presents a multi-criterion decision-aided maintenance model with three criteria that have more influence on decision making: reliability, maintenance cost, and maintenance downtime. The Bayesian approach has been applied to confront maintenance failure data shortage. Therefore, the model seeks to make the best compromise between these three criteria and establish replacement intervals using Preference Ranking Organization Method for Enrichment Evaluation (PROMETHEE II), integrating the Bayesian approach with regard to the preference of the decision maker to the problem. Finally, using a numerical application, the model has been illustrated, and for a visual realization and an illustrative sensitivity analysis, PROMETHEE GAIA (the visual interactive module) has been used. Use of PROMETHEE II and PROMETHEE GAIA has been made with Decision Lab software. A sensitivity analysis has been made to verify the robustness of certain parameters of the model.
\end{abstract}

Keywords: Preventive maintenance, Age-dependent PM policy, PROMETHEE II, Bayesian approach, PROMETHEE GAIA

\section{Background}

Global trade, higher levels of automation, and the desire to apply lean production are some factors that increase the demand for effective maintenance (Salonen and Deleryd 2011). In recent decades, industrial and service systems have realized that establishing a proper maintenance policy plays an essential role in achieving their objectives (Cholasuke et al. 2004; van der Meulen et al. 2008). It can also lead to maximizing their profits (Alsyouf 2009). One of the most important reasons of considering maintenance as a crucial concept can be its large contribution of operating budget in organizations with heavy investments in machinery and equipment (Tsang et al. 1999). Moreover, because of the development of technology, competitive industrial and service systems should make use of more advanced machinery which need higher levels of maintenance because they are more complex and more difficult to control (Alsyouf 2009). The role of maintenance in modern

\footnotetext{
* Correspondence: elahe_faghihinia60@yahoo.com

${ }^{1}$ Department of Industrial Engineering, Islamic Azad University of Najafabad, Isfahan 8514143131, Iran

Full list of author information is available at the end of the article
}

manufacturing systems is becoming even more important with companies adopting maintenance as a profitgenerating business element (Sharma and Yadava 2011). In order to avoid failures at random times and the effect of such failures on the performance of systems that appear as a reducing production rate and loss of quality of the products, maintenance management is required to reduce the loss of system operating time and the number of defective parts produced (Tsarouhas 2011).

Maintenance is becoming a critical functional area in most types of organizations and systems including construction, manufacturing, transportation, etc. This increasing role of maintenance is reflected in its high cost, which is estimated to be around $30 \%$ of the total running cost of modern manufacturing and construction businesses. As such, planning for maintenance is becoming an essential part of planning for the whole organization (AlTurky 2011). Therefore, common practices like repairing a system when there is a problem have to be substituted by monitoring the system condition and planning the maintenance intervals (Cavalcante and De Almedia 2007). Also, effective maintenance can extend the equipment life, 
improve equipment availability, and restore the equipment to a good condition (Swanson 2001). Well-defined maintenance system will ensure optimal performance of the machineries (Oberschmidt et al. 2010). Therefore, it can not only improve the quality of goods and services but also satisfy and rather exceed customers' demands especially in service sectors (Oke and Charles-Owaba 2006). The importance of running proper maintenance policies in organizations has led researchers to define maintenance in several ways. For example, Tsarouhas (2011) defines maintenance as a tool whose objectives are to increase the time to failure and reduce the repair time of equipment. Al-Turky (2011) defines it as the activities related to maintaining a certain level of availability and reliability of the system and its components and the system ability to perform with a standard level of quality. Still, maintenance can be defined as the combination of all technical efforts which can retain an item or equipment, or restore it to an acceptable operating condition (Dhillon 2002; British Standards Institute Staff 1993). With regard to the critical role of maintenance in improving reliability, preventing unexpected system failures and reducing maintenance costs, maintenance and replacement problems have been widely studied from different perspectives in the literature, and several models have been proposed (Wang 2002). All of them seek to elaborate on different maintenance problems and propose more rational solutions. This paper proposes a multi-criterion decision-aided maintenance model with regard to three criteria important to selecting the best maintenance policy. They are maintenance costs, reliability, and maintenance downtime criteria. This model not only considers the various aspects of a maintenance problem but also attends to the preference of a decision maker. Furthermore, Bayesian approach has been applied to overcome failure data shortage. Finally, a sensitivity analysis has been made to verify the robustness of certain parameters of the model.

\section{Preventive maintenance}

Complex equipment and machinery systems used in the production of goods and delivery of services constitute the vast majority of capital invested in industry (Savsar 2011). As time passes, the machines age and unplanned failures occur, causing the system performance to drift away from its initial state. In fact, no piece of equipment or system can continue to function without failure forever; however, carefully it might have been designed and manufactured (Samar Ali and Kannan 2011). System deterioration is often reflected in higher production costs and lower product quality. Therefore, the function of the system must be periodically restored to the desired level; this is practically achieved by maintenance operations. Proper maintenance can increase the reliability of a piece of equipment or a system at regular intervals (Samar Ali and Kannan 2011). Such maintenance is known as preventive maintenance (PM); it is done periodically before the failure of the system; hence, it is different from corrective or repair maintenance, which is carried out only after the failure of the item or the system (Savsar 2011). To keep production costs down while maintaining good product quality, PM is often performed on systems subject to deterioration (Savsar 2011). The probability of failure would increase as a machine is aged, and it would sharply decrease after a planned PM is implemented (Savsar 2011).

It should be pointed out quickly that the maintenance actions which are normally classified as corrective maintenance $(\mathrm{CM})$ include all actions performed as a result of a failure to restore an item to a specified working condition, while PM includes all actions performed on an operating equipment to restore it to a better condition (Oberschmidt et al. 2010). Moreover, making use of $\mathrm{CM}$ could be costly for organizations because most of the time, CM takes a long time to have an acceptable effect on a failed system or component (Nakagawa 2005). Thus, it can be disastrous for some systems where failures and interruptions could be dangerous. For example, we can consider military systems, aircraft, and health systems where a small mistake can lead to a horrible disaster (Cavalcante and De Almedia 2008).

Also, the costs of applying CM in organizations are usually three or four times bigger than applying PM (Chitra 2003). So, it would be more rational to study PM models as a basic concept for the purpose of proposing an optimum maintenance model. In addition, PM policies are used for contexts where the component failure rate increases by age and usage (Cavalcante and De Almedia 2008).

\section{PM models}

Although a lot of maintenance models have been created during the past decades, there are few maintenance policies on which all the other maintenance models can be based (Wang 2002). There is a categorization proposed by Wang (2002). According to him, there are seven categories of maintenance policies, of which five are preventive. They are age-dependent PM, periodic PM, failure limit, sequential PM, and repair limit.

According to age-dependent PM policy, a unit is replaced at the predetermined time $T$ or in the case of failure, whichever occurs first, where $T$ is a constant (Barlow and Hunter 1960). The given time $T$ is measured from the time of the last replacement (Wang 2002). According to periodic PM policy, a unit is preventively maintained at fixed time intervals independent of the failure history of the unit and repaired at intervening failures where $T$ is a constant. 
According to failure limit policy, PM is performed only when the failure rate or other reliability indices of a unit reach a predetermined level, and intervening failures are corrected by repairs. According to sequential PM policy, a unit is preventively maintained at unequal time intervals under the sequential PM policy. Usually, the time intervals become shorter and shorter as time passes, considering that most units need more frequent maintenance with increased ages.

According to repair limit PM policy, when a unit fails, the repair cost is estimated and repair is undertaken if the estimated cost is less than a predetermined limit; otherwise, the unit is replaced. He also indicates that the age-dependent policy can be the most common and popular PM. In several recent works, age-replacement policy was extensively studied. The age-replacement policy and its extensions belong to the age-dependant policy (Wang 2002).

Therefore, by taking a look at PM models, we can realize that there are a large variety of preventive maintenance models and their extensions, so it would be necessary to specify a given problem to resolve in this context. Therefore, the age-replacement policy has been chosen as the basis for this research. Also in this paper, it is assumed that the replacement of a piece of equipment or part gives the system a goodas-new performance.

In addition, there are two requisites for PM implementation in each system where (Cavalcante and De Almedia 2008):

1. The replacement cost of a component $\left(c_{\mathrm{p}}\right)$ before failures should be less than the cost of replacement due to failures $\left(c_{\mathrm{f}}\right)$.

2. The component failure rate should increase by age and usage.

This paper proposes a multi-criterion decision-aided model with three criteria which deals with the problem of the replacement times. It determines the best timing and frequency for replacing components by taking into account three criteria, which are the total cost of maintenance per unit of time, the reliability, and the total maintenance downtime per unit of time. Thus, after choosing the policy followed by this research, it is important to describe the importance of these three criteria in maintenance decision making.

Maintenance has become one of the most important issues in the manufacturing industry due to high costs involved (Savsar 2011). In production systems, maintenance managers concentrate on reducing maintenance costs (Cavalcante and De Almedia 2008). In manufacturing organizations, maintenance-related costs are estimated to be $25 \%$ of the overall operating cost (Cross 1988).
According to Maggard and Rhyne (1992), the maintenance can represent between $10 \%$ and $40 \%$ of the production cost in a company. Coetzee (2004) means that the numbers should be $15 \%$ to $50 \%$. Bevilacqua and Braglia (2000) state that maintenance costs can represent as much as $15 \%$ to $70 \%$ of the total production cost. So, it seems plausible that the maintenance costs may very well represent over $15 \%$ of the total production cost in industry (Salonen and Deleryd 2011). These findings show that maintenance cost cannot be ignored by maintenance managers.

But there are several situations in some organizations where other criteria like reliability, availability, downtime, etc., play critical roles in systems. Earlier, researchers were using the optimization criteria as minimizing system maintenance cost rate, ignoring the reliability performance. In fact, minimizing system maintenance cost rate may not imply maximizing the system reliability measures. Sometimes, when the maintenance cost rate is minimized, the system reliability measures are also so low that they are not acceptable in practice (Sharma and Yadava 2011).

According to Cavalcante and De Almedia (2008), in the services sector, the decision maker can show a preference for minimizing undesirable consequences which are difficult to measure in financial units. Because in this context, the customer is in direct contact with the production, and frequent interruption in the service can negatively affect the desire of the customer to enter into a new contract with that supplier or can lead the customer to cancel the current contract, which is unacceptable in competitive markets today.

Generally, managers would like to see their system run as planned, and an unscheduled event such as a machine failure will disrupt the smooth running of the plant. Sometimes, the marketing department brings emergency product orders for important customers, and a system failure may result in severe losses (Chareonsuk et al. 1997).

Therefore, looking at the cost criterion as the most important factor to establish an optimum maintenance model is a very dangerous perspective for industrial and service systems, especially for systems where failures and interruptions could be disastrous. It is moreover impossible to capture all of a system's effects in a cost function.

In some systems, the reliability criterion plays an essential role and which must be taken into account when an optimum maintenance model is to be established. Therefore, in a number of situations, maintenance managers mean to consider reliability as a separate criterion (Chareonsuk et al. 1997).

Reliability, $R(t)$, is the probability that a component or system will perform its design function for a specified mission time, given the operating conditions. 
Table 1 Preference functions (adapted from Brans and Mareschal 2005)

Generalized criterion
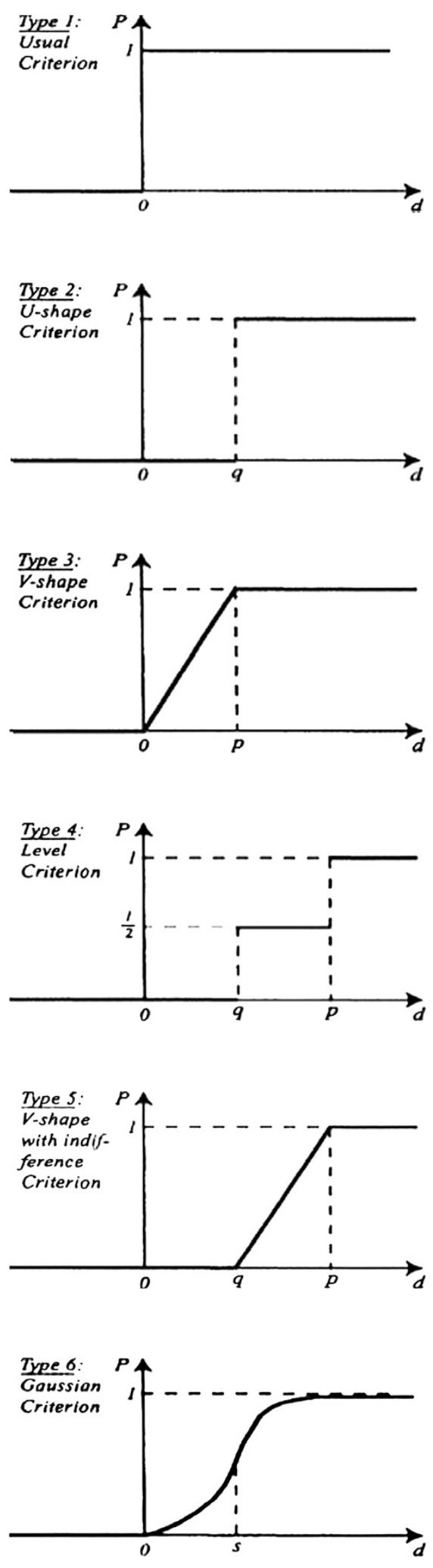

$s=(p+q) / 2$

\section{Definition}

$P(d)= \begin{cases}0 & d \leq 0 \\ 1 & d>0\end{cases}$

$P(d)=\left\{\begin{array}{l}0 \mathrm{~d} \leq \mathrm{q} \\ 1 \mathrm{~d}>\mathrm{q}\end{array}\right.$

Q

$P(d)= \begin{cases}0 & d \leq 0 \\ \frac{d}{p} & 0 \leq \mathrm{d} \leq \mathrm{p} \\ 1 & d>p\end{cases}$

P

$P(d)= \begin{cases}1 & d \leq \mathrm{q} \\ \frac{1}{2} & q<d \leq \mathrm{p} \\ 1 & d>p\end{cases}$

$p, q$

$P(d)= \begin{cases}0 & d \leq q \\ \frac{d-q}{p-q} & q<d \leq p \\ 1 & d>p\end{cases}$

$$
P(d)= \begin{cases}0 & d^{2} \\ 1-e^{-\frac{d^{2}}{2 e^{2}}} & d>0\end{cases}
$$

Parameters to fix 


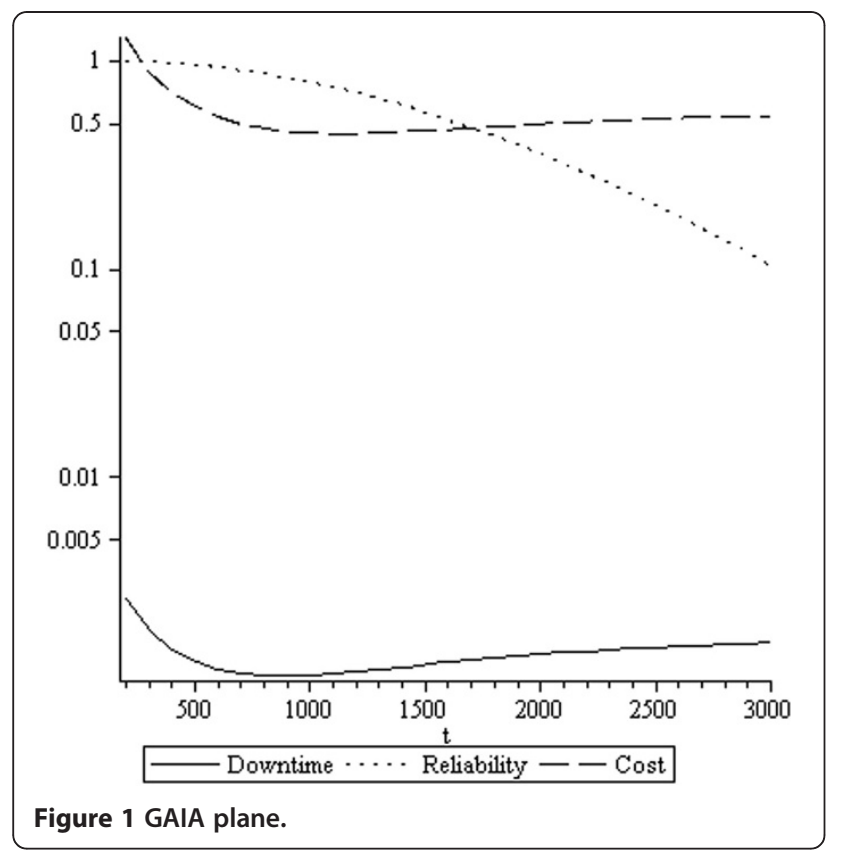

There is another factor added to the model maintenance downtime. A question might be in order here. How important is this factor in maintenance decision making?

Chareonsuk et. al (1997) considered a situation where preventive maintenance cost is not high, so in order to keep the system at a high level of reliability, the maintenance department decides to run maintenance programs very frequently. This can lead to very frequent shutdowns where the production department will be reluctant to attend to the preventive maintenance programs. Therefore, they will either cause forced postponed preventive maintenance or schedule when there is no production (for example, at night when it would be inconvenient for maintenance people). This problem can postpone maintenance programs. Therefore, in practice, maintenance programs cannot be fully maintained (Chareonsuk et al. 1997).

Besides, downtime is very important and must not be neglected because the minimum downtime for a piece of equipment could result in undesirable consequences (Cavalcante and De Almedia 2008). With respect to the importance of taking into account the criterion of cost
Table 2 Model's parameters

\begin{tabular}{cccccccc}
\hline $\boldsymbol{c}_{\mathrm{a}}(\mathbf{\$})$ & $\boldsymbol{c}_{\mathrm{b}}(\mathbf{\$})$ & $\boldsymbol{T}_{\mathbf{f}}$ (days) & $\boldsymbol{T}_{\mathrm{p}}$ (days) & $\boldsymbol{\beta}_{\mathbf{1}}$ & $\boldsymbol{\eta}_{\mathbf{1}}$ & $\boldsymbol{\beta}_{\mathbf{2}}$ & $\boldsymbol{\eta}_{\mathbf{2}}$ \\
\hline 1,000 & 250 & 3 & 0.5 & 3.40 & 4.15 & 2.80 & 2200 \\
\hline
\end{tabular}

per unit of time, the reliability criterion and the maintenance downtime in making a proper maintenance decision need to be integrated in considering maintenance scheduling in a multi-criterion environment. This paper seeks to determine PM intervals during which the three criteria are in their best compromise with each other.

\section{Bayesian approach}

Mathematics has had an important role to extend maintenance models. Stochastic mathematical models have been developed to improve system reliability, prevent unexpected failures, and reduce maintenance costs (Zhang 2005). The use of mathematical modeling for this purpose is well established in the literature (Sortrakul and Cassady 2007). A number of surveys have been published by some authors in this area.

McCall (1965) proposes a survey of researches on maintenance policies subject to stochastic failure. Pierskalla and Voelker (1976) also present a survey on maintenance models for deteriorating systems. Sherif and Smith (1981) review various maintenance models subject to failure and propose a classification.

Sharma and Yavada (2011) present a survey on maintenance optimization models. More surveys can be found in the studies of Valdez-Flores and Feldman (1989), Cho and Parlar (1991), Dekker (1996), and Wang (2002).

This part explains the mathematical requirements. In order to plan a maintenance program in this research, a failure distribution is needed which has a wear-out characteristic, namely the failure rate should increase with age. The Weibull model is a most prevalent distribution that satisfies this perquisite. It can be shown to be of the form:

$$
\mathrm{f}(\mathrm{t})=\frac{\beta}{\eta} \cdot\left(\frac{t}{\eta}\right)^{\beta-1} \quad \beta, \eta>0, t>0
$$

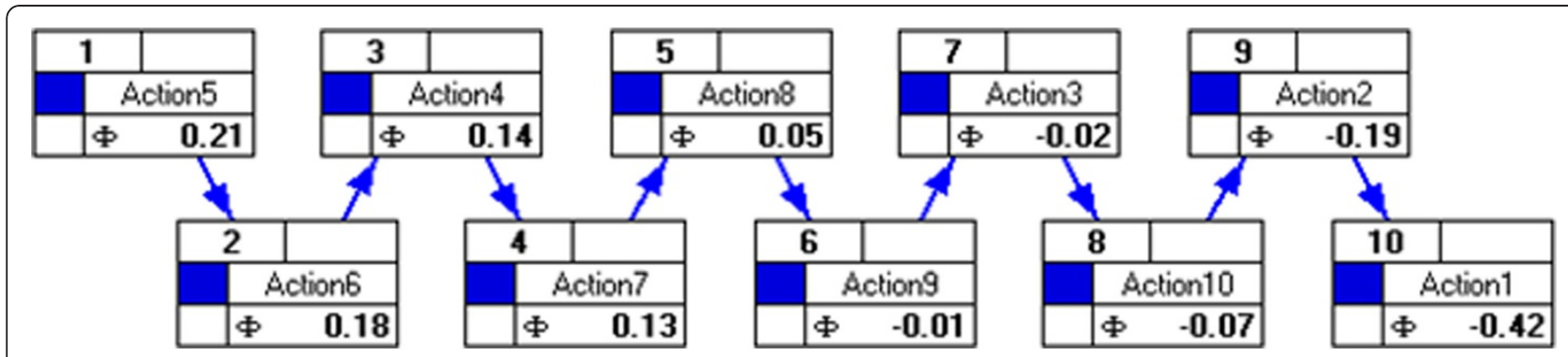

Figure 2 Decision model flowchart. 
Table 3 Performances of alternatives $\left(g_{i}(t)\right)$

\begin{tabular}{|c|c|c|c|}
\hline$T$ (days) & $R(t)$ & $C(t)$ & $D(t)$ \\
\hline 200 & 0.9904 & 1.2874 & 0.0030 \\
\hline 300 & 0.9797 & 0.8890 & 0.0018 \\
\hline 400 & 0.9643 & 0.6996 & 0.0014 \\
\hline 500 & 0.9441 & 0.5944 & 0.0013 \\
\hline 600 & 0.9192 & 0.5315 & 0.0012 \\
\hline 700 & 0.8899 & 0.4928 & 0.0011 \\
\hline 800 & 0.8566 & 0.4690 & 0.0011 \\
\hline 900 & 0.8198 & 0.4551 & 0.0011 \\
\hline 1,000 & 0.7802 & 0.4478 & 0.0011 \\
\hline 1,100 & 0.7383 & 0.4452 & 0.0012 \\
\hline 1,200 & 0.6947 & 0.4458 & 0.0012 \\
\hline 1,300 & 0.6502 & 0.4489 & 0.0012 \\
\hline 1,400 & 0.6051 & 0.4534 & 0.0012 \\
\hline 1,500 & 0.5604 & 0.4591 & 0.0013 \\
\hline 1,600 & 0.5162 & 0.4654 & 0.0013 \\
\hline 1,700 & 0.4730 & 0.4722 & 0.0013 \\
\hline 1,800 & 0.4314 & 0.4792 & 0.0014 \\
\hline 1,900 & 0.3916 & 0.4861 & 0.0014 \\
\hline 2,000 & 0.3538 & 0.4930 & 0.0014 \\
\hline 2,100 & 0.3182 & 0.4996 & 0.0014 \\
\hline 2,200 & 0.2849 & 0.5060 & 0.0015 \\
\hline 2,300 & 0.2541 & 0.5120 & 0.0015 \\
\hline 2,400 & 0.2258 & 0.5179 & 0.0015 \\
\hline 2,500 & 0.1998 & 0.5230 & 0.0015 \\
\hline 2,600 & 0.1762 & 0.5274 & 0.0016 \\
\hline 2,700 & 0.1549 & 0.5318 & 0.0016 \\
\hline 2,800 & 0.1358 & 0.5357 & 0.0016 \\
\hline 2,900 & 0.1187 & 0.5393 & 0.0016 \\
\hline 3,000 & 0.1034 & 0.5425 & 0.0016 \\
\hline
\end{tabular}

where $\eta$ is called the scale parameter; $\beta$, the shape parameter. In order to establish optimum maintenance intervals, we need to recognize the failure behavior of system or component. Thus, the parameters of the failure distribution of system or component should be estimated. In order to estimate the distribution function parameters, historical data are often used; therefore, a large quantity of data is needed to obtain reliable estimates. But because of the rapid growth of industry, often sufficient historical information about the components or system failures is not available (Chen and Popova 2002). Often, only a few failure data are available, and in some cases where there are enough data, they are not reliable (Scarf 1997). Therefore, estimation parameters from failure data is another difficulty in maintenance program (Cavalcante and De Almedia 2008).

However, during the process of the system production and its operating time, reliability engineers and specialists

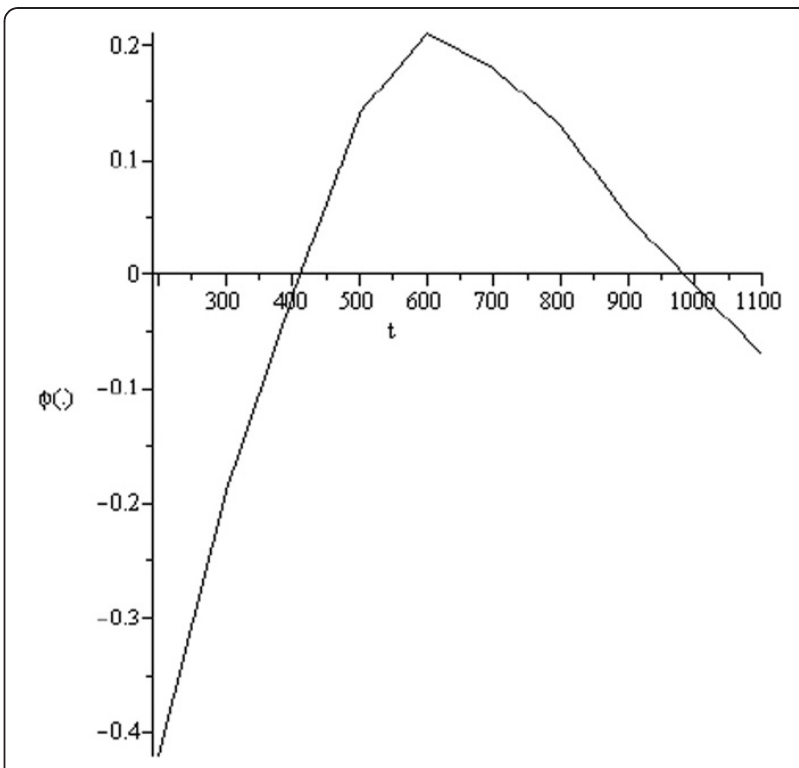

Figure 3 Criteria relationships.

find out by intuition about its failure behavior (Chen and Popova 2002). Combined with actual observations, this information can provide better assessment of the failure rate parameters. Bayesian analysis is one way to enter this information into the decision-making process in order to make a more objective decision. Therefore, a major advantage of Bayesian analysis is when only a few data are available. Bayesian statistics provides a way to incorporate specialist advice about a system into the maintenance model. The Bayesian maintenance models have been used frequently to establish maintenance policies in recent decades (Cavalcante and De Almedia 2008).

Some authors such as Jorgenson et al. (1967), McCall (1965), Dayanlk and Gurler (2002), Wilson and Benmerzouga (1995), Sheu et al. (2001), Juang and Anderson (2004), Kallen and Van Noortwijk (2005), Makis and Jardine (1992), McNaught and Chan (2011), and many others have used this approach in different maintenance models (Oberschmidt et al. 2010).

Finally, using a Weibull distribution to model failure in cases of incomplete data, specialist knowledge can be used. Therefore, the Weibull distribution parameters are considered random variables with a priori distributions representing specialist knowledge: $\mu(\eta)$ and $\mu(\beta)$.

Table 4 Criteria thresholds

\begin{tabular}{lcc}
\hline Criteria & \multicolumn{2}{c}{ Thresholds } \\
\cline { 2 - 3 } & $\boldsymbol{p}$ & $\boldsymbol{Q}$ \\
\hline Reliability & 0.0300 & 0.1000 \\
Cost & 0.0150 & 0.2000 \\
Downtime & 0.0011 & 0.0001 \\
\hline
\end{tabular}


Table 5 Criteria weights

\begin{tabular}{lc}
\hline Criteria & Weights (\%) \\
\hline Reliability & 35 \\
Cost & 40 \\
Downtime & 25 \\
\hline
\end{tabular}

After estimating the Weibull parameters, evaluation of the cost, reliability, and maintenance downtime criteria can be obtained using the model, and then a multi-criterion decision with PROMETHEE methods can be made.

\section{PROMETHEE: one of the multi-criterion decision-making methods}

By taking a look at decision-making problems in the real world, it can be seen that most of them are multicriterion. Decision making in many contexts depends on several criteria not just on one criterion. This can be seen in many fields such as industries, economics, finance, or politics. Making decisions in maintenance programs can be a multi-criterion decision problem. According to Shyjith et al. (2008), selecting a maintenance policy based on a few factors makes it unrealistic. There is a need to consider maintenance problems as multi-criterion. This outlook can give a comprehensive view to maintenance management. So, it can be critical to consider maintenance problems as multi-criterion especially in systems that take into account only the cost criterion for making a maintenance decision because in some systems with special conditions, it could result in

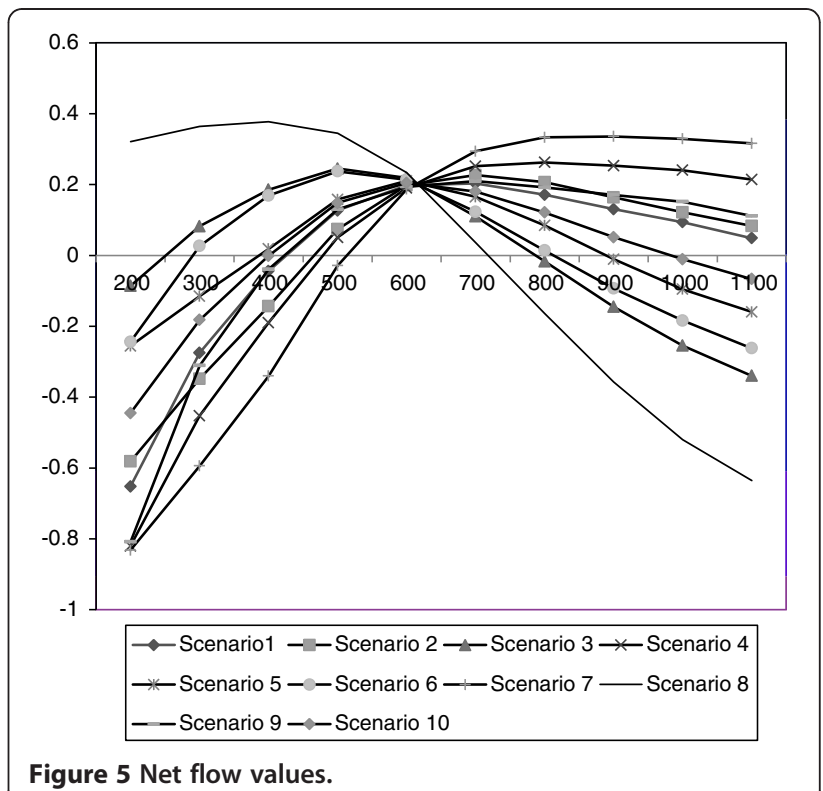

disasters. If the maintenance department only wants to look at the cost criterion, it could lead it to ignoring other criteria like reliability or maintenance downtime.

A multi-criterion problem is mathematically defined as (Brans and Mareschal 1994 a,b; Brans et al. 1984):

$$
\operatorname{Max}\left\{g_{1}(a), g_{1}(a), \ldots, g_{i}(a), \ldots, g_{k}(a) \cdot \mid \cdot a \in A\right\}
$$

where $A$ is a finite set of $n$ possible alternatives $\left\{\mathrm{a}_{1}\right.$, $\left.\mathrm{a}_{2}, \ldots, \mathrm{a}_{n}\right\}$, and $\left\{g_{1}(),. g_{2}(),. \ldots, g_{\mathrm{k}}().\right\}$ is a set of evaluation

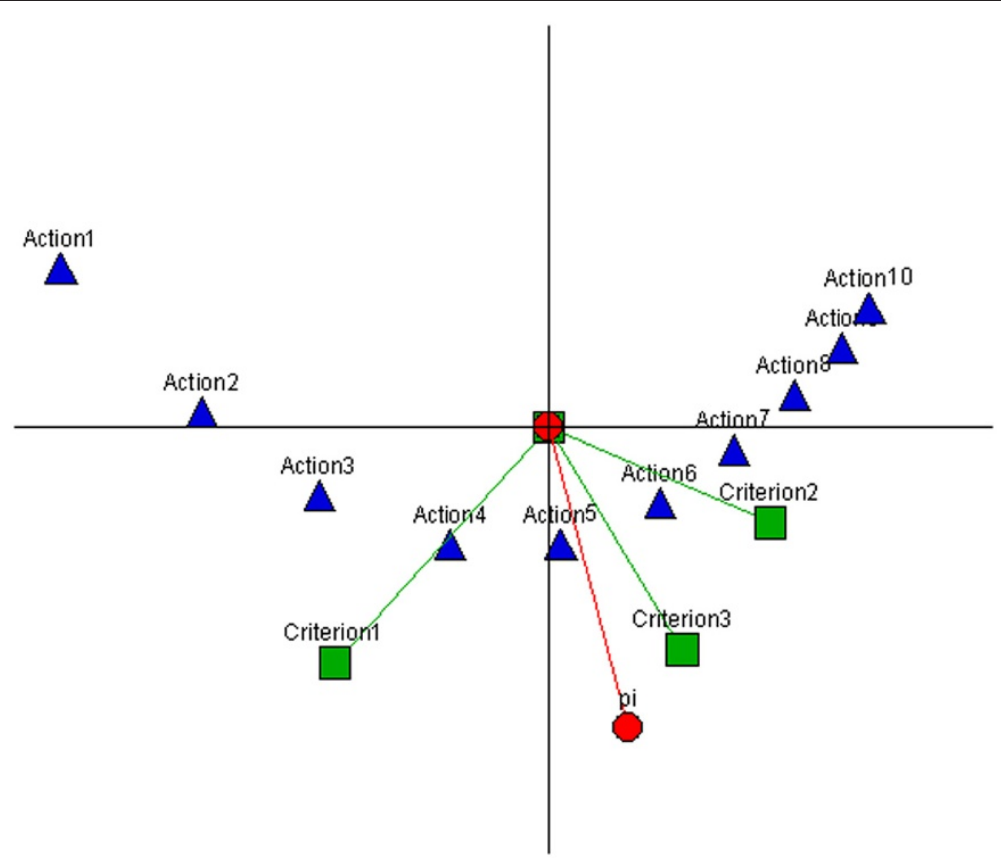

Figure 4 PROMETHEE II ranking 1. 
Table 6 Scenarios

\begin{tabular}{lccc}
\hline Scenarios & $\begin{array}{c}\text { Reliability weight } \\
\text { (\%) }\end{array}$ & $\begin{array}{c}\text { Cost weight } \\
\text { (\%) }\end{array}$ & $\begin{array}{c}\text { Downtime weight } \\
\text { (\%) }\end{array}$ \\
\hline 1 & 20 & 25 & 55 \\
2 & 25 & 55 & 20 \\
3 & 55 & 20 & 25 \\
4 & 10 & 45 & 45 \\
5 & 45 & 45 & 10 \\
6 & 45 & 10 & 45 \\
7 & 10 & 80 & 10 \\
8 & 80 & 10 & 10 \\
9 & 10 & 10 & 80 \\
10 & 33 & 33 & 34 \\
\hline
\end{tabular}

criteria. They are called the basic data of a multi-criterion problem (Brans and Mareschal 1994a,b; Brans et al. 1984).

In recent years, many decision-aid methods have been proposed. The PROMETHEE methods are one group of these methods consisting of seven. PROMETHEE methods developed by Brans are one of the best known and most widely used outranking approaches in many applications (Makis and Jardine 1992). A comprehensive overview of applications can be found in Behzadian et al. (2010). In general, outranking approaches are based on comparisons of pairs of alternatives (Oberschmidt et al. 2010). The PROMETHEE methods have been frequently used in many fields, and their success is due to their mathematical processes and the fact that they are easy to use by decision makers (Brans and Mareschal 1994a,b; Brans et al. 1984).

The input required concerns the evaluation of the criteria for all of the alternatives considered as well as the weightings needed to reflect their relative importance. In order to apply PROMETHEE, first, the performance of the alternatives regarding all criteria needs to be determined. Then, alternatives are compared in pairs for each criterion based on generalized preference functions. Based on the weighted sum of single criterion preferences, positive and negative outranking flows are calculated as a measure of dominance of alternatives. Criteria weights reflect the subjective relative importance of the criteria. Based on positive and negative outranking flows, a partial preorder of alternatives can be defined according to PROMETHEE I. The net outranking flow can also be calculated to avoid incomparabilities and define a complete preorder on the set of alternatives according to PROMETHEE II (Oberschmidt et al. 2010). After that, PROMETHEE III that ranks alternatives based on intervals and PROMETHEE IV, the continuous case, were developed by Brans and Mareschal.
They also proposed the visual interactive module GAIA in 1988, which provides an interesting graphical view to support the PROMETHEE methodology. In 1992 and 1994, Brans and Mareschal extended these two types: PROMETHEE V, an extension of PROMETHEE I and II where a subset of alternatives has to be selected by considering a set of constraints, and PROMETHEE VI, an extension of the results from PROMETHEE I and II that provides the decision maker with the freedom to think of the weight in terms of intervals, rather than of exact values (Brans and Mareschal 1994a,b; Brans et al. 1984; Cavalcante and De Almedia 2008).

The PROMETHEE II method has been chosen for outranking results in this research, and the PROMETHEE GAIA has been chosen for a visual realization and sensitivity analysis of the results in this research. The reasons for selecting these methods are fast use, easy-to-analyze results, and a flexible comparison process (Cavalcante and De Almedia 2008). Moreover, the information which needed to use PROMETHEE and GAIA is easy and clear to define for decision makers (Brans et al. 1984; Brans and Mareschal 1994b).

To make use of PROMETHEE methods, first, the two following phases should be passed (Brans and Mareschal 1994a,b; Brans et al. 1984; Cavalcante and De Almedia 2008):

1. Calculating the evaluation of each alternative for each criterion : $\mathrm{g}_{\mathrm{i}}(\mathrm{a})$; and

2. Calculating the differences between the evaluations of the alternatives within each criterion:

$$
\mathrm{d}_{\mathrm{i}}(\mathrm{a}, \mathrm{b})=\mathrm{g}_{\mathrm{i}}(\mathrm{a})-\mathrm{g}_{\mathrm{i}}(\mathrm{b})
$$

We also need two types of additional information to run PROMETHEE (Brans and Mareschal 1994a):

1. The information between the criteria that consists of the relative importance of the different criteria and which depends on the preferences of a decision maker. They are shown by $w_{j}, j=1,2, \ldots, k$. They are considered as norm weights.

2. The information within the criteria is referred to assign a preference function to each criterion. After calculating the differences between each two alternatives for a criterion, $d_{\mathrm{i}}(\mathrm{a}, \mathrm{b})$, the decision maker's preferences are needed to identify the indifference threshold $(q)$ that is the largest deviation to ignore and the preference threshold $(p)$, i.e., the smallest deviation considered to be a

Table 7 Scenario 1

\begin{tabular}{|c|c|c|c|c|c|c|c|c|c|c|}
\hline$t$ (days) & 200 & 300 & 400 & 500 & 600 & 700 & 800 & 900 & 1,000 & 1,100 \\
\hline$\overline{\varphi(.)}$ & -0.6523 & -0.2751 & -0.0442 & 0.1267 & 0.198 & 0.2029 & 0.1712 & 0.1305 & 0.0937 & 0.0486 \\
\hline
\end{tabular}


Table 8 Scenario 2

\begin{tabular}{lcccccccccc}
\hline $\boldsymbol{t}$ (days) & $\mathbf{2 0 0}$ & $\mathbf{3 0 0}$ & $\mathbf{4 0 0}$ & $\mathbf{5 0 0}$ & $\mathbf{6 0 0}$ & $\mathbf{7 0 0}$ & $\mathbf{8 0 0}$ & $\mathbf{9 0 0}$ & $\mathbf{1 , 0 0 0}$ & $\mathbf{1 , 1 0 0}$ \\
\hline$\varphi()$. & -0.5816 & -0.3483 & -0.1435 & 0.0738 & 0.1979 & 0.2268 & 0.2065 & 0.1637 & 0.1217 & 0.0831 \\
\hline
\end{tabular}

preference relation between two alternatives. So in this phase, decision maker selects a generalized criterion, $F_{\mathrm{i}}\left(d_{\mathrm{i}}(\mathrm{a}, \mathrm{b})\right)$, to model his preferences for every criterion. After specifying the function parameters by the decision maker, the preference function can be obtained.

$$
\begin{aligned}
& \mathrm{P}_{\mathrm{i}}(\mathrm{a}, \mathrm{b})=\mathrm{F}_{\mathrm{i}}\left(\mathrm{d}_{\mathrm{i}}(\mathrm{a}, \mathrm{b})\right) \mathrm{d}_{\mathrm{i}}(\mathrm{a}, \mathrm{b})>0 \\
& \mathrm{P}_{\mathrm{i}}(\mathrm{a}, \mathrm{b})=0 \quad \mathrm{~d}_{\mathrm{i}}(\mathrm{a}, \mathrm{b})<0
\end{aligned}
$$

There are six preference functions suggested for decision makers. These functions have satisfied the conditions of many real-world problems. They are shown in Table 1.

The PROMETHEE II method has been chosen to rank the alternatives. This ranking is based on net flow $\phi$ (a) (Brans and Mareschal 1994a; Cavalcante and De Almedia 2008):

$$
\phi(\mathrm{a})=\frac{1}{n-1} \sum x \in A \sum_{i}^{k}[P i(a, x)-P i(x, a)] w i .
$$

Therefore, each alternative can get the highest score on the net flow which is the best compromise solution. Because of considering the differences $d_{\mathrm{i}}$ to rank the alternatives in PROMETHEE II, more information get lost (Brans and Mareschal 1994a,b; Brans et al. 1984). In order to overcome and have a better realization of the situations of alternatives and criteria, this paper has made use of PROMETHEE GAIA. The GAIA plane will be shown and interpreted in Figure 1. The GAIA plane can also provide a powerful graphical visualization tool for a decision maker (Brans et al. 1984; Brans and Mareschal 1994b). The specific power of each criterion, the conflicting aspects, and the attributes of each alternative on the different criteria are GAIA plane's specific qualities (Brans et al. 1984). Finally, a sensitivity analysis usually serves to demonstrate the influence of different weightings on the results of the assessment (Oberschmidt et al. 2010).

\section{Results and discussions}

\section{Mathematical configurations of the criteria}

The goal of this paper is to evaluate the different time alternatives and rank them according to the decision maker's preferences and to the values of the three criteria in each alternative. Therefore, the mathematical configurations of these criteria are needed. To achieve this goal, the mathematical equations of these three criteria have been illustrated.

The first equation is the reliability formula which is based on reliability definition. It is the probability of lack of a component or system failure before time $t$. Thus, it is mathematically defined as follows, where $f(t)$ is the density function of the component failure behavior:

$$
R(t)=\int_{t}^{\infty} f(t) d t
$$

The second and third equations are the maintenance cost and maintenance downtime formulas, respectively. They were created by Jardine (1973). The details of these formulas are defined as follows:

$c_{\mathrm{p}}$ : Replacement cost before failure

$c_{\mathrm{f}}$ : Replacement cost due to failure

$T_{\mathrm{p}}$ : The time taken to make a preventive replacement

$T_{\mathrm{f}}$ : The time taken to make a replacement due to failure

$$
\begin{aligned}
\left.C(t)=\frac{C \mathrm{p} \times R(t)+C_{\mathrm{f}} \times[1-R(t)]}{\left(t+T_{\mathrm{p}}\right) \times R(t)+\left(\left(\int_{-\infty}^{t} x f(x) d x /{ }_{[1-R(t)]}\right)+T_{\mathrm{f}}\right.}\right) \\
\times[1-R(t)]
\end{aligned}
$$

$$
\begin{aligned}
\left.D(t)=\frac{T \mathrm{p} \times R(t)+T_{\mathrm{f}} \times[1-R(t)]}{\left(t+T_{\mathrm{p}}\right) \times R(t)+\left(\left(\int_{-\infty}^{t} x f(x) d x\right)_{[1-R(t)]}\right)+T_{\mathrm{f}}}\right) \\
\times[1-R(t)]
\end{aligned}
$$

Because of the absence of the maintenance data and uncertainty in both parameters of the component failure distribution function, specialist information can be used to estimate them. Hence, by making use of Bayesian approach, the parameters of Weibull distribution are

Table 9 Scenario 3

\begin{tabular}{lcccccccccc}
\hline $\boldsymbol{t}$ (days) & $\mathbf{2 0 0}$ & $\mathbf{3 0 0}$ & $\mathbf{4 0 0}$ & $\mathbf{5 0 0}$ & $\mathbf{6 0 0}$ & $\mathbf{7 0 0}$ & $\mathbf{8 0 0}$ & $\mathbf{9 0 0}$ & $\mathbf{1 , 0 0 0}$ & $\mathbf{1 , 1 0 0}$ \\
\hline$\varphi()$. & -0.0859 & 0.0824 & 0.1855 & 0.2452 & 0.2185 & 0.1102 & -0.0167 & -0.1452 & -0.2545 & -0.3396 \\
\hline
\end{tabular}


Table 10 Scenario 4

\begin{tabular}{|c|c|c|c|c|c|c|c|c|c|c|}
\hline$t$ (days) & 200 & 300 & 400 & 500 & 600 & 700 & 800 & 900 & 1,000 & 1,100 \\
\hline$\varphi()$. & -0.8203 & -0.4524 & -0.1897 & 0.0506 & 0.1903 & 0.2518 & 0.2624 & 0.2531 & 0.2403 & 0.2139 \\
\hline
\end{tabular}

considered random variables, and their distributions should be assessed from the specialist information on these variables $\pi(\eta)$ and $\pi(\beta)$. Because of uncertainty on parameters $\eta$ and $\beta$, the computations of reliability, cost, and downtime criteria should incorporate the distributions $\pi(\eta)$ and $\pi(\beta)$ that follow the Weibull distribution. Hence, according to Cavalcante and De Almedia (2008), reliability and cost criteria formulas follow these equations:

$$
E(R(t ; \eta, \beta))=\int_{t}^{\infty} \int_{-\infty}^{\infty} \int_{-\infty}^{\infty} \pi(\eta) \pi(\beta) f(x ; \eta, \beta) d \eta d \beta d x
$$

$$
\begin{gathered}
C(t)=\frac{C \mathrm{p} \times R(t)+C_{\mathrm{f}} \times[1-R(t)]}{\left(t+T_{\mathrm{p}}\right) \times R(t)+\left(\int_{-\infty}^{t} \int_{-\infty}^{\infty} \int_{-\infty}^{\infty} x \pi(\eta) \pi(\beta)\right.} \\
f(x ; \eta, \beta) d \eta d \beta d x) \\
\times T_{\mathrm{f}} \times[1-R(t)]
\end{gathered}
$$

At the end the third equation, which calculates the maintenance downtime, this equation follows:

$$
\begin{gathered}
D(t)=\frac{T \mathrm{p} \times R(t)+T_{\mathrm{f}} \times[1-R(t)]}{\left(t+T_{\mathrm{p}}\right) \times R(t)+\left(\int_{-\infty}^{t} \int_{-\infty}^{\infty} \int_{-\infty}^{\infty} x \pi(\eta) \pi(\beta)\right.} \\
f(x ; \eta, \beta) d \eta d \beta d x) \\
\times T_{\mathrm{f}} \times[1-R(t)]
\end{gathered}
$$

\section{The decision model process}

Up to this point, all the details of the model have been described. In order to describe the process of the model, the following 14 steps need to be completed. The flowchart of the model has been brought in Figure 2.

1. Determine the time alternatives $T_{\mathrm{i}}$ by decision makers, those which are applicable for doing PM;

2. Determine Bayesian parameters $\beta_{1}, \eta_{1}, \beta_{2}, \eta_{2}$;

3. Determine $c_{\mathrm{p}}, c_{\mathrm{f}}, T_{\mathrm{p}}, T_{\mathrm{f}}$;

4. Calculate $g_{\mathrm{i}}(\mathrm{a})$ where $g_{1}=R(t), g_{2}=C(t), g_{3}=D(t)$ for all of the time alternatives $T$;
5. Analyze the values of the three criteria and determine the acceptable alternatives;

6. Calculate $d_{\mathrm{i}}(\mathrm{a}, \mathrm{b})=g_{\mathrm{i}}(\mathrm{a})-g_{\mathrm{i}}(\mathrm{b})$ for each two time alternatives;

7. Determine $w_{j}, j=1 . .3$;

8. Determine $F_{j}\left(d_{\mathrm{i}}(\mathrm{a}, \mathrm{b})\right), j=1 . .3$ and their thresholds;

9. Calculate $\phi\left(\mathrm{a}_{\mathrm{i}}\right)$ for each time alternatives;

10. Rank the time alternatives by the values of $\phi\left(\mathrm{a}_{\mathrm{i}}\right)$;

11. Draw the GAIA plane;

12. Analyze the sensitivity of the results into variation of $w_{j} j=1 . .3$;

13. Choose the best time alternative;

14. Stop

\section{Numerical application}

In order to evaluate the practical aspects of the model and to see the model's value in practice, a numerical application will be needed. In fact, by a numerical example, the effectiveness of the model can be observed, and decision makers can get a better idea of it. Therefore, this section presents a hypothetical example which is closer to the real situation of a component.

The data consist of information about the prior distributions of $\eta$ and $\beta$. Therefore, there are $\beta_{1}$ and $\eta_{1}$ which are the parameters of the Weibull distribution that belongs to $\beta$ and $\beta_{2}$ and $\eta_{2}$, the parameters of the Weibull distribution that belongs to $\eta$. They have been obtained from specialist information. Also, the replacement costs before $\left(c_{\mathrm{p}}\right)$ and after failure $\left(c_{\mathrm{f}}\right)$, the time taken to make a replacement before $(T \mathrm{p})$ and after failure $\left(T_{\mathrm{f}}\right)$ are needed. These values are shown in Table 2.

Also, the time alternatives incorporate the interval between 200 and 3,000 days with an interval of 100 days between the alternatives. The performances of the alternatives are calculated for the three criteria and are shown in Table 3 . The calculations in relation to Table 3 have been done by making use of Maple 13 software.

In order to see the relationships between these three criteria in the time alternatives whose values have been plugged in Table 3, they have been drawn as three curves

\begin{tabular}{|c|c|c|c|c|c|c|c|c|c|c|}
\hline$t$ (days) & 200 & 300 & 400 & 500 & 600 & 700 & 800 & 900 & 1,000 & 1,100 \\
\hline$\overline{\varphi(.)}$ & -0.2556 & -0.1151 & 0.0184 & 0.1578 & 0.2104 & 0.1652 & 0.0847 & -0.0107 & -0.0954 & -0.1597 \\
\hline
\end{tabular}
in Figure 3. The horizontal axes show the time alternatives from 200 to 3,000 days and the vertical axes show the values of three criteria in each the time alternative.

It is obvious that the cost criterion should be minimized. As seen in Table 3 and Figure 3, this criterion

Table 11 Scenario 5 
Table 12 Scenario 6

\begin{tabular}{|c|c|c|c|c|c|c|c|c|c|c|}
\hline$\overline{t \text { (days) }}$ & 200 & 300 & 400 & 500 & 600 & 700 & 800 & 900 & 1,000 & 1,100 \\
\hline$\varphi()$. & -0.2439 & 0.0265 & 0.1691 & 0.2373 & 0.2138 & 0.1229 & 0.0139 & -0.0934 & -0.184 & -0.2621 \\
\hline
\end{tabular}

gets its best value in the time alternative 1,100 days. Also, the reliability criterion should be maximized. As seen in Table 3 and Figure 3, it is descending during the time alternatives. In fact, it has its best value at point zero. The downtime criterion also needs to be minimized, and as can be seen in Table 3 and Figure 3, it gets its minimum value in 1,200 days. Therefore, for the time alternatives greater than 1,100 days, the cost criterion increases during the time and simultaneously the reliability criterion is descending and the downtime criterion is increasing during the time. Therefore, evaluating the alternatives greater than 1,100 days is not useful. They cannot result in the best compromise response between these three criteria. Hence, they can be neglected. Finally, there are ten alternatives which need to be ranked. There are the time alternatives from 200 to 1,100 days.

In order to make use of the PROMETHEE II ranking, the preference function is determined as the linear function, the fifth among the Decision Lab functions (according to Table 1), and it has been used for all of the three criteria. Their thresholds have been determined according to the preference of the decision maker, and they are shown in Table 4.

Moreover, the PROMETHEE methods need criteria weights which are chosen by the decision maker. The weights which are assumed for the three criteria in this paper are shown in Table 5.

After determining the whole data needed in order to use the Decision Lab software and rank the alternatives, they can be put in the software. Decision Lab 2000 is a multi-criterion analysis and decision-making software. Decision Lab 2000 was designed to be applied to various multi-criterion decision problems and designed for all Windows platforms. After putting the required data in the software, it ranks the time alternatives immediately. The PROMETHEE II ranking is used for the ten-time alternatives chosen as shown in Figure 4.

As said before, the PROMETHEE II method ranks the alternatives by calculating the $\phi($.$) values. Therefore,$ each alternative capable of getting the highest score in $\phi$ (.) is the best compromise solution. Figure 5 shows that the best compromise solution is Action 5 which presents the time alternative 600 days. In order to see the variations between the alternatives in the value of the net flow, Figure 5 can be illustrative. It shows that alternative
600 days has made the highest score in net flow; therefore, it is the best compromise solution that PROMETHEE II has determined.

\section{GAIA plane}

GAIA plane is a useful tool to evaluate a decision-making problem. It can show the relationship between criteria and alternatives. In order to get a better understanding of the problem, the GAIA plane of the problem has been shown in Figure 1. The alternatives are shown by triangleshaped points, and the criteria are shown by squareshaped points. There is an axis named $\mathrm{Pi}$. It is called the PROMETHEE decision axis, namely, each alternative which is closer to this axis than the others is better to choose.

Criteria 2 and 3 show similar preferences because they are approximately in the same direction. Moreover, in GAIA plane, each alternative which is closer to a criterion should be good at the criterion. It can be seen about alternative 4 at criterion 1 , alternative 5 at criterion 3 , and alternative 6 at criterion 2 .

It is so obvious that alternatives $1,2,3$, and 4 are not good at criterion 2 or alternatives $6,7,8,9$ and 10 are not good at criterion 1 . Alternative 6 is between criteria 2 and 3 ; therefore, it is good at both criteria. Alternative 5 is between criteria 1 and 3; therefore, it is good at both criteria. But seen in Figure 1, alternative 5 is closer to Pi than others. Therefore, it should be the best compromise solution.

As seen in Table 5, these results are obtained from specific weights. Therefore, if the weights change, the ranking will change. Changing the weights will only change the situation of axis $\mathrm{Pi}$ and the situations of the criteria, and the alternatives will remain unchanged. Therefore, it can be seen how this ranking is sensitive to the variation of the weights. In order to answer this question, a sensitivity analysis has been made.

\section{Sensitivity analysis}

With a good sensitivity analysis, it is possible to obtain more interpretative results which enhance the decisionmaker understanding of the maintenance problem and to evaluate whether solutions proposed by the model are sensitive to parameter change. Therefore, in this section,

Table 13 Scenario 7

\begin{tabular}{lcccccccccc}
\hline $\boldsymbol{t}$ (days) & $\mathbf{2 0 0}$ & $\mathbf{3 0 0}$ & $\mathbf{4 0 0}$ & $\mathbf{5 0 0}$ & $\mathbf{6 0 0}$ & $\mathbf{7 0 0}$ & $\mathbf{8 0 0}$ & $\mathbf{9 0 0}$ & $\mathbf{1 , 0 0 0}$ & $\mathbf{1 , 1 0 0}$ \\
\hline$\varphi()$. & -0.832 & -0.594 & -0.3403 & -0.0289 & 0.1869 & 0.2941 & 0.3332 & 0.3358 & 0.3289 & 0.3163 \\
\hline
\end{tabular}


Table 14 Scenario 8

\begin{tabular}{|c|c|c|c|c|c|c|c|c|c|c|}
\hline$t$ (days) & 200 & 300 & 400 & 500 & 600 & 700 & 800 & 900 & 1,000 & 1,100 \\
\hline$\varphi()$. & 0.3209 & 0.3638 & 0.3772 & 0.3445 & 0.2339 & 0.0362 & -0.1639 & -0.3573 & -0.5196 & -0.6357 \\
\hline
\end{tabular}

the research has tried to test different weights to get a better idea about the problem.

For the purpose of analyzing the sensitivity of the results to the changing weights, different weights need to be chosen and tested. In order to choose some weights, ten scenarios have been defined in Table 6:

For each scenario, the net flow values of the alternative have been calculated by Decision Lab software and are brought in Tables 7, 8, 9, 10, 11, 12, 13, 14, 15, and 16 .

It should be noticed that the values in italics show that they are the best answers of those scenarios based on the maximum values of $\phi($.)

Moreover, to achieve a visual realization of the results of net flows $\phi$ for the scenarios, they are shown in Figure 6.

At first, it is obvious that the variation of the weights changes the ranking of the alternatives. Therefore, it is important to properly determine the weights. The decision maker should study the condition of the system carefully and then define the weights regarding their preferences. With regard to the tables, it is obvious that alternatives 600 days and 700 days are more frequently used as the best compromise solutions.

For the purpose of studying the behavior of each criterion, the weight of the criterion can be changed at a constant rate, and the weights of the other two criteria need to be change simultaneously equally. For this purpose, the following eight scenarios have been defined for each criterion, and the movement of the decision axis $\mathrm{Pi}$ has been in mind:

Scenario $1=\{20,25,55\}$

Scenario $2=\{25,55,20\}$

Scenario $3=\{55,20,25\}$

Scenario $4=\{10,45,45\}$

Scenario $5=\{45,45,10\}$

Scenario $6=\{45,10,45\}$

Scenario $7=\{10,10,80\}$

Scenario $8=\{80,10,10\}$

Scenario $9=\{10,10,80\}$

Scenario $10=\{33,33,34\}$

So, the observation of the behavior of the reliability criterion shows that by moving from scenario 1 to scenario 8 , the decision axis moves from alternative 800 days to alternative 400 days. The observation of the behavior of the cost criterion shows that by moving from scenario 1 to scenario 8 , the decision axis moves from alternative 500 days to alternative 900 days.

The observation of the behavior of the downtime criterion shows that by moving from scenario 1 to scenario 8 , the decision axis moves from alternative 600 days to alternative 700 days. These observations show that the two criteria of reliability and cost are conflicting. Also, the alternative downtime does not change widely. It only moves between two alternatives.

\section{Gap of research}

It is obvious that researchers in the field of maintenance try to make the best policy that is most compatible with their systems. Thus, there are many researches in this field with different focuses. Tsarouhas (2011) performs a comparative study of performance evaluation between four pizza production lines. He estimates the reliability and maintainability of the lines, focusing on the maintenance and repair strategies necessary for maintenance staff to keep equipment operating at the required level of reliability, which leads to the situation where lines are operating more profitably through reduced maintenance costs and increased productivity and efficiency (Tsang et al. 1999). Savsar (2011) presents a practical application of modeling and analysis procedures for maintenance operations in the context of an oil filling plant. System is analyzed under the current and a proposed PM policy, which reduced the equipment down time due to CMs (Samar Ali and Kannan 2011). Mohideen et al. (2011) presents a proposal to minimize the recovery time and the breakdown cost in the system in a construction plant (McNaught and Chan 2011). Sharma and Yadava (2011) review the literature on maintenance optimization models and associated case studies (Scarf 1997). They conclude that a good research work has been reported on optimization to bring down maintenance cost. The maintenance cost optimization work has been done on selecting maintenance policies, equipment availability, spare parts management, workforce scheduling, and interval of inspection frequency based on different simulation model. This finding shows that in most cases other criteria, like reliability, availability, down time, have been ignored in the choice of a maintenance policy. Sharma and Yadava (2011) also show that the applications

Table 15 Scenario 9

\begin{tabular}{lcccccccccc}
\hline $\boldsymbol{t}$ (days) & $\mathbf{2 0 0}$ & $\mathbf{3 0 0}$ & $\mathbf{4 0 0}$ & $\mathbf{5 0 0}$ & $\mathbf{6 0 0}$ & $\mathbf{7 0 0}$ & $\mathbf{8 0 0}$ & $\mathbf{9 0 0}$ & $\mathbf{1 , 0 0 0}$ & $\mathbf{1 , 1 0 0}$ \\
\hline$\varphi()$. & -0.8086 & -0.3108 & -0.0391 & 0.1301 & 0.1937 & 0.2095 & 0.1917 & 0.1705 & 0.1516 & 0.1114 \\
\hline
\end{tabular}


Table 16 Scenario 10

\begin{tabular}{lcccccccccc}
\hline $\boldsymbol{t}$ (days) & $\mathbf{2 0 0}$ & $\mathbf{3 0 0}$ & $\mathbf{4 0 0}$ & $\mathbf{5 0 0}$ & $\mathbf{6 0 0}$ & $\mathbf{7 0 0}$ & $\mathbf{8 0 0}$ & $\mathbf{9 0 0}$ & $\mathbf{1 , 0 0 0}$ & $\mathbf{1 , 1 0 0}$ \\
\hline$\varphi()$. & -0.4452 & -0.1822 & -0.0013 & 0.1483 & 0.2046 & 0.1804 & 0.1213 & 0.0514 & -0.0107 & -0.0667 \\
\hline
\end{tabular}

on DSS of optimization models are very limited in industry and not much has been from literature. As seen before, the application of PROMETHEE in this research is one answer to this lack.

A point of strength in this model is specifying periodic frequency for PM operations by the analysts and those involved in the system. In those model where optimum time for PM operations is calculated by the model itself, ordinarily, the obtained answers and the output of the model are not immediately applicable and would need adaptations and modifications, since the maintenance operation is not performed independently and would require coordination with the production and operations sections, with production scheduling section, and even at times other engineering sections. In fact, the answer produced is not applicable and would generally require concurrence with the conditions at the workshop, and this is while modification would distance our answer from optimal conditions. In the present model, frequency is determined beforehand by the analyst and those involved in the system, and their opinions are thoroughly incorporated into the system; thus, the obtained

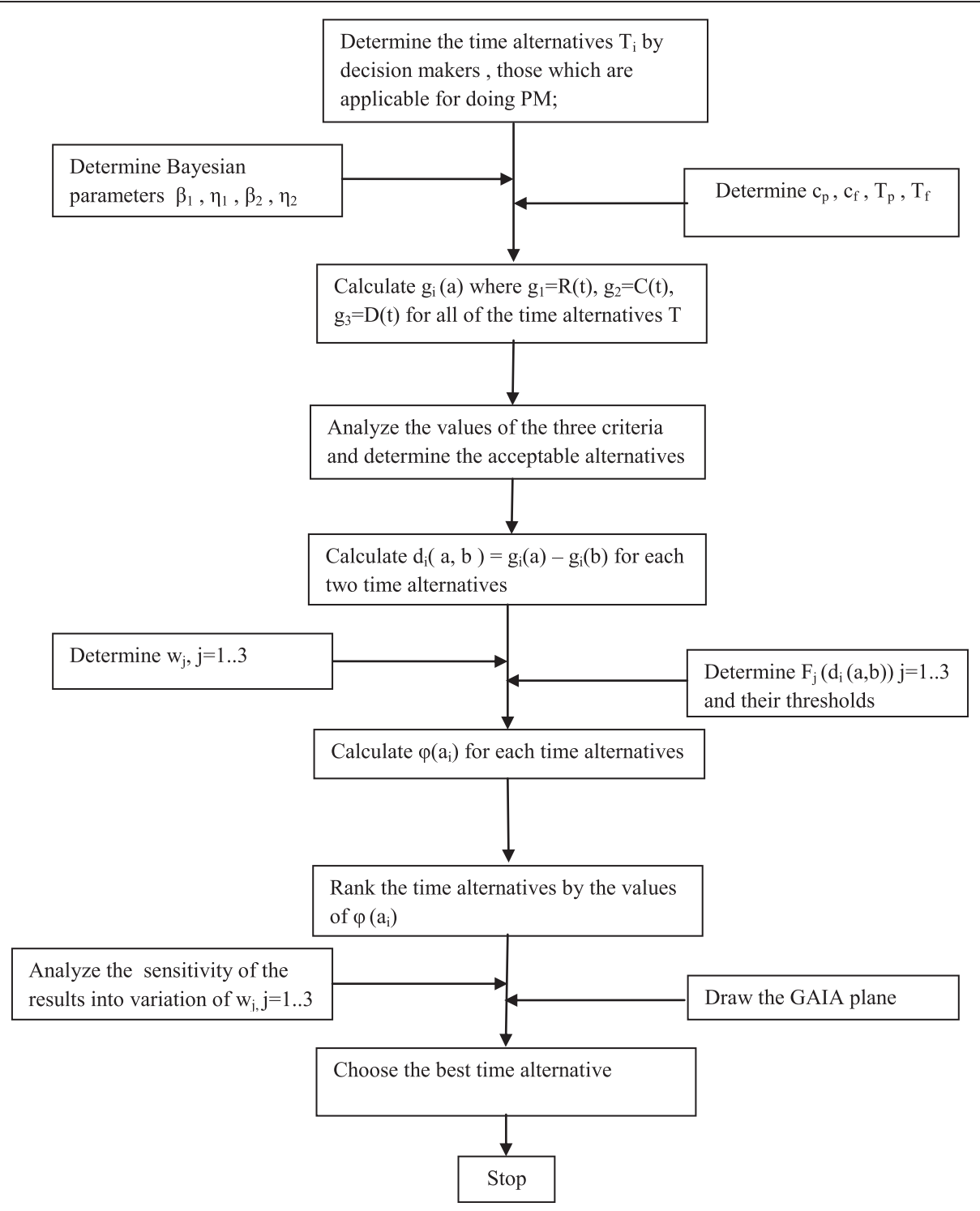

Figure 6 Sensitivity analysis. 
answers and, in fact, the output of the model are immediately and without any alterations applicable and can be utilized.

\section{Conclusion}

This paper presents a multi-criterion decision-making model for preventive maintenance planning which determines the best compromise time for replacement of a certain item based on more than one criterion. This model also envisions the difficulty with the shortage of maintenance failure data by making use of Bayesian approach and PROMETHEE II for decision making.

In most cases, when maintenance managers try to determine the best policy for their systems, they only consider the cost criterion as the most important and the only criterion to be taken into account. This is a very dangerous point of view. Therefore, one of the most important goals that this paper seeks to reach is to give a broader view of the maintenance managers by considering more than one criterion in making an appropriate decision for replacement of an item in PM problems. Taking these three criteria into consideration, this paper does not imply that they are the most important criteria that need to be considered for replacement of an item in PM planning. It implies that in order to make a complete and timely PM planning which considers many aspects of the problem, decision makers have to study the problem completely and consider the factors which affect a PM planning for replacement of item because ignoring the influential factors in different situations can lead to disastrous results. Therefore, it is not true to say that there are some factors which are important for all the systems. Moreover, changing the weights shows that for different preferences of decision makers and different conditions of the systems, different weights are needed. Therefore, the structure of the model can be applied to different systems and situations.

\section{Methods}

In this section, the methods used in this research have been reviewed. In this research, multi-criterion decision making methods have been used to model a maintenance planning. Three criteria as reliability, maintenance cost, and maintenance downtime have been considered to make the best replacement intervals for preventive maintenance. In order to compensate the loss of historical data, Bayesian analysis has been used. This research has chosen PROMETHEE II method to outrank the results because of fast use, easy-to-analyze results, and a flexible comparison process. This method requires criteria weights reflecting the subjective relative importance of the criteria by decision makers. In this research, in order to analyze sensitivity and graphical visualization of results, PROMETHEE GAIA has been used.

\section{Competing interests}

The authors declare that they have no competing interests.

\section{Authors' contributions}

Both authors have participated in completing every section of the paper equally. All authors read and approved the final manuscript.

\section{Author details}

${ }^{1}$ Department of Industrial Engineering, Islamic Azad University of Najafabad, Isfahan 8514143131, Iran. ${ }^{2}$ Department of Industrial Engineering, Isfahan University of Technology, Isfahan 8415683111, Iran.

Received: 31 May 2011 Accepted: 5 March 2012

Published: 16 August 2012

\section{References}

Alsyouf I (2009) Maintenance practices in Swedish industries: survey results. Int J Prod Econ 121:212-223

Al-Turky U (2011) A framework for strategic planning in maintenance. J Qual Mainten Eng 17(2):150-162

Barlow RE, Hunter LC (1960) Optimum preventive maintenance polices. Oper Res 8:90-100

Behzadian M, Kazemzadeh RB, Albadvi A, Aghdasi M (2010) PROMETHEE: a comprehensive literature review on methodologies and applications. Eur J Oper Res 200(1):198-215

Bevilacqua M, Braglia M (2000) The analytic hierarchy process applied to maintenance strategy selection. Reliab Eng Syst Saf 70(1):71-83

Brans JP, Mareschal B (1994a) The PROMCALC and GAIA decision-support system for multicriteria decision aid. Decis Support Syst 12(4-5):297-310

Brans JP, Mareschal B (1994b) The PROMETHEE-GAIA decision support system for multicriteria investigations. Investigation Operativa 4(2):107-117

Brans JP, Mareschal B (2005) PROMETHEE methods. In: Figueira J, Greco S, Ehrgott M (eds) Multiple criteria decision analysis: state of the art surveys. Springer, Boston

Brans JP, Mareschal B, Vincke P (1984) PROMETHEE: a new family of outranking methods in multicriteria analysis. Oper Res 84:477-490

British Standards Institute Staff (1993) Glossary of terms used in terotechnology. BSI, London

Cavalcante CAV, De Almedia AT (2007) A multicriteria decision aiding model using PROMETHEE III for preventive maintenance planning under uncertain conditions. J Qual Mainten Eng 13:385-397

Cavalcante CAV, De Almedia AT (2008) A preventive maintenance decision model based on multicriteria method PROMETHEE II integrated with Bayesian approach. IMA J Manag Math 16:1-16

Chareonsuk C, Nagarur N, Tabucanon MT (1997) A multicriteria approach to the selection of preventive maintenance intervals. Int J Prod Econ 49:55-64

Cholasuke C, Bhardwa R, Antony J (2004) The status of maintenance management in UK manufacturing organisations: results from a pilot survey. J Qual Mainten Eng 10(1):5-15

Chitra T (2003) Life based maintenance policy for minimum cost, In: Annual reliability and maintainability (RAMS). IEEE Press, NY, Bangalore, India, February 28, 2003, pp 470-pp 474

Cho D, Parlar M (1991) A survey of maintenance models for multi-unit systems. Eur J Oper Res 51:1-23

Chen T, Popova E (2002) Maintenance policies with two-dimensional warranty. Reliability Engineering and Systems Safety 77:61-69

Coetzee JL (2004) Maintenance. Trafford Publishing, Victoria

Cross M (1988) Raising the value of maintenance in the corporate environment. Manag Res News 1(3):8-11

Dayanlk S, Gurler U (2002) An adaptive Bayesian replacement policy with minimal repair. Oper Res 50:552-558

Dekker R (1996) Applications of maintenance optimization models: a review and analysis. Reliab Eng Syst Saf 51:229-240

Dhillon BS (2002) Engineering maintenance. CRC Press, Boca Raton, USA

Jardine AKS (1973) Maintenance, replacement and reliability. John Wiley \& Sons, New York

Jorgenson DW, Mccall JJ, Radner R (1967) Optimal replacement policy. NorthHolland, Amsterdam

Juang MG, Anderson G (2004) A Bayesian method on adaptive preventive maintenance problem. Eur J Oper Res 155:455-473 
Kallen MJ, Van Noortwijk JM (2005) Optimal maintenance decisions under imperfect inspection. Reliab Eng Syst Saf 90:177-185

Maggard B, Rhyne D (1992) Total productive maintenance: a timely integration of production and maintenance. Prod Inventory Manag J 33(4):6-10

van der Meulen P, Petraitis M, Pannese P (2008) Advanced semiconductor manufacturing conference. In: Design for maintenance. IEEE Press, NY, Washington DC, USA, May 5-7, 2008, pp 278-281

McCall JJ (1965) Maintenance policies for stochastically failing equipment: a survey. Manag Sci 11:493-624

McNaught K, Chan A (2011) Bayesian networks in manufacturing. J Manuf Tech Manag 22(6):734-747

Makis V, Jardine AKS (1992) Optimal replacement in the proportional hazards model. INFOR 30:172

Mohideen APB, Ramachandran M, Narasimmalu RR (2011) Construction plant breakdown criticality analysis - part 1: UAE perspective. Benchmark Int J 18(4):472-489

Nakagawa T (2005) Maintenance theory of reliability. Springer, London

Oberschmidt J, Geldermann J, Ludwig J, Schmehl M (2010) Modified PROMETHEE approach for assessing energy technologies. Int J En Sect Manag 4(2):183-212

Oke SA, Charles-Owaba OE (2006) Application of fuzzy logic control model to Gantt charting preventive maintenance scheduling. Int J Qual Reliab Manag 23(4):441-459

Pierskalla WP, Voelker JA (1976) A survey of maintenance models: the control and surveillance of deteriorating systems. Nav Res Logistics Q 23:353-388

Salonen A, Deleryd M (2011) Cost of poor maintenance: a concept for maintenance performance improvement. J Qual Mainten Eng 17(1):63-73

Samar Ali S, Kannan S (2011) A diagnostic approach to Weibull-Weibull stressstrength model and its generalization. Int J Qual Reliab Manag 28(4):451-463

Savsar M (2011) Analysis and modeling of maintenance operations in the context of an oil filling plant. J Manuf Tech Manag 22(5):679-697

Scarf PA (1997) On the application of mathematical models in maintenance. Eur J Oper Res 99:493-506

Sharma A, Yadava GS (2011) A literature review and future perspectives on maintenance optimization. J Qual Mainten Eng 17(1):5-25

Sherif SML (1981) Optimal maintenance models for systems subject to failure-a review. Nav Res Logistics Q 28:47-74

Shyjith K, llangkumaran M, Kumanan S (2008) Multi-criteria decision-making approach to evaluate optimum maintenance strategy in textile industry. J Qual Mainten Eng 14(4):375-386

Sheu SH, Yeh RH, Lin YB, Juang MG (2001) A Bayesian approach to an adaptive preventive maintenance model. Reliab Eng Syst Saf 71:33-44

Sortrakul N, Cassady CR (2007) Genetic algorithms for total weighted expected tardiness integrated preventive maintenance planning and production scheduling for a single machine. J Qual Mainten Eng 13(1):49-61

Swanson L (2001) Linking maintenance strategies to performance. Int J Prod Econ 70(3):237-244

Tsang AHC, Jardine AKS, Kolodny H (1999) Measuring maintenance performance a holistic approach. J Qual Mainten Eng 19(7):691-715

Tsarouhas PH (2011) A comparative study of performance evaluation based on field failure data for food production lines. J Qual Mainten Eng 17(1):26-39

Valdez-Flores C, Feldman RM (1989) A survey of preventive maintenance models for stochastic deteriorating single-unit systems. Nav Logistics Q 36:419-446

Wang H (2002) A survey of maintenance policies of deteriorating systems. Eur J Oper Res 139:469-489

Wilson JG, Benmerzouga A (1995) Bayesian group replacement policies. Oper Res 43:471-476

Zhang J (2005) Maintenance planning and cost effective replacement strategies. University of Alberta, Canada

doi:10.1186/2251-712X-8-14

Cite this article as: Faghihinia and Mollaverdi: Building a maintenance policy through a

multi-criterion decision-making model. Journal of Industrial Engineering

International 2012 8:14

Submit your manuscript to a SpringerOpen ${ }^{\odot}$ journal and benefit from:

- Convenient online submission

- Rigorous peer review

- Immediate publication on acceptance

- Open access: articles freely available online

- High visibility within the field

- Retaining the copyright to your article

Submit your next manuscript at $>$ springeropen.com 